\title{
Ovotransferrin as a novel drug-targeting molecule for cancer chemotherapy
}

\author{
Hisham R Ibrahim*, Daiichi Miyawaki, Takeshi Miyata \\ Department of Biochemistry and Biotechnology, Faculty of Agriculture, Kagoshima University, Kagoshima 890-0065, Japan
}

\begin{abstract}
In spite of the numerous discoveries of new anticancer drugs that work on different intracellular targets, many of these drugs have considerable drawback as they are nonselective thus causing adverse side effects on normal cells. This study is aimed to explore the potential of ovotransferrin (OTf) as a carrier molecule to allow specific targeting of anticancer drugs to cancer cells via transferrin receptor (TfR). Receptor binding assay provided evidence that OTf bind to the transferrin-receptor (TfR) of human colon cancer cells. Two anticancer drugs, carboplatin (cbp) and paclitaxel (PTX), were non-covalently conjugated with OTf, at different mole ratios, through freeze-condensation. The two OTf conjugates showed superior anti-proliferative activities against human colon carcinoma (HCT-116) and human breast carcinoma (MCF-7) cells compared to the activities of free drugs, with OTf-cbp being the most potent conjugate. The conjugates with low drug loading inhibited cell growth more efficient than the high drug loaded conjugates. Fluorescence staining with acridine orange and propidium iodide showed that HCT-116 cells treated with OTfcbp or OTf-PTX exhibited red fluorescence, indicating that PI entered to the nuclei as the cell membrane lost its integrity. The red fluorescence was accompanied by chromatin condensation and fragmentation, indicates apoptosis. The results demonstrate, for the first time, that OTf could be utilized to specifically target drugs via TfR-mediated endocytosis to cancer cells and will help to pave the way for clinical studies as a potential targeting molecule.
\end{abstract}

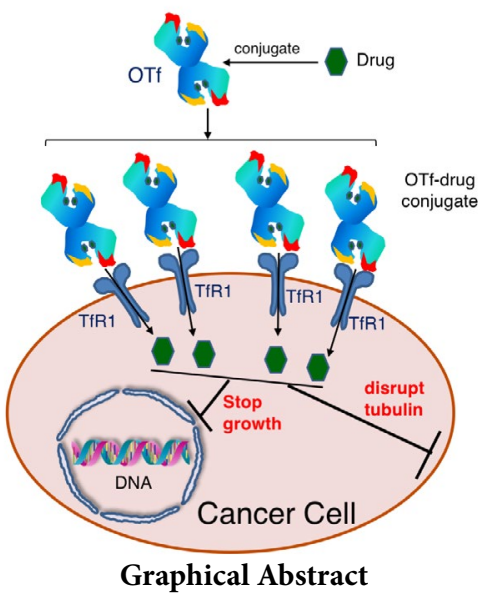

\begin{abstract}
Abbreviations: OTf: Ovotransferrin, OTf-cbp(n): Ovotransferrincarboplatin conjugate (drug: OTf mole ratio), OTf-PTX(n): Ovotransferrin-paclitaxel conjugate (drug:OTf mole ratio), TfR: Transferrin receptor

\section{Introduction}

Cancer is as a result of the unregulated growth of cancer cells because it lost the normal regulatory mechanisms that control cell growth and become insensitive to growth inhibitory signals. The search for novel drug that can be used effectively for the unregulated growth of cancer cells has become a challenge. Chemotherapy is the most commonly used type of cancer treatment works by killing the fast-growing cancer cells or stopping the growth of cancer cells. Chemotherapy not only affects cancer cells, but also could damage or slow the growth of healthy cells thereby causing side effects.
\end{abstract}

Among common chemotherapies currently in use are [1] antimetabolites, work by interefering with metabolism of proliferating cells such as methotrexate and 5-fluorouracil; [2] alkylating agents, work by damaging DNA and result in death of growing cells such as cisplatin and carboplatin; and [3] mitosis inhibitors, work by targeting microtubules required in cell division such as taxol and paclitaxel. The

${ }^{\star}$ Correspondence to: Hisham R Ibrahim, Department of Biochemistry and Biotechnology, Faculty of Agriculture, Kagoshima University, Kagoshima 8900065, Japan; E-mail: hishamri@chem.agri.kagoshima-u.ac.jp

Key words: Ovotransferrin, Transferrin receptor, Cancer therapy, Protein-drug binding, Targeted drug delivery

Received: October 01, 2020; Accepted: October 13, 2020; Published: October 16,2020 
majority of these anticancer drugs exert high systemic toxicity due to damage to normal cells, develop multidrug resistance with prolonged treatment, and show unfavorable biopharmaceutical properties such as poor water solubility and low permeability $[1,2]$.

As the permeability of these drugs to cancer cells is relatively poor, higher doses are required, leading to elevated side effects and an increased incidence of multiple drug resistance. Therefore, it is necessary to develop chemotherapeutics that can actively target cancer cells, thereby reducing adverse side effects while improving therapeutic efficacy.

Technological advances, such as targeted drug-delivery, help to improve the biopharmaceutical properties, efficacy, and reduce side effects of existing drugs. Anticancer drug-targeting approach is achieved by conjugating the drug to a carrier molecule that bind to over expressed receptors or transporters on the surface of cancer cells [1,3-5]. Conventional drug carriers, such as nanoparticles, micellar structures and liposomes, have demonstrated opportunities in therapeutic formulations. However, the lack of biodegradation and potential toxicity poses significant limitations to the use of these carriers in therapeutic applications. Thus, the development of novel drug delivery carrier with better targeting ability is crucially needed for cancer chemotherapy.

All types of cells contain various receptors, transporters and channels located on the surface of cell, plasma membrane, that are primarily involved in the uptake of small molecules, such as nutrients and signaling molecules [6,7]. These receptors are targets for drug delivery for the treatment of number of diseases [8-10]. Most cell receptors can recognize, specifically, certain proteins (antigens) then internalize them into the cell. Transferrin receptor (TfR) is one of the surface receptors that are over-expressed on rapidly multiplying cancer cells $[11,12]$. The TfR is expressed on the plasma membrane of cancer cells approximately 10 folds higher than normal cells, whereas it mediates intracellular delivery of $\mathrm{Fe}^{3+}$ bound to transferrin via endocytosis process $[11,13]$. Transferrins are a family of eukaryotic homologous iron-binding proteins, blood serotransferrin (Tf), milk lactoferrin (Lf), egg white ovotransferrin (OTf) and membrane-bound melanotransferrin (MTf), that function in the transport of iron to cells [14]. The high expression of TfR on cancer cells makes it an attractive target for cancer therapy $[12,15,16]$.

Members of transferrin family share similar sequence and structure, but they differ in their TfR binding properties [17-19]. Few studies used human $\mathrm{Tf}$ as drug carrier to target drugs via $\mathrm{TfR}$ receptors on breast cancer and glioblastoma cells $[16,20,21]$.

Functional evidence that both $\mathrm{N}$-terminal (N-lobe) and C-terminal (C-lobe) domains of OTf are recognized by and bind to the TfR of human lymphocyte with the same affinity as that of Tf has been reported [22]. The results differ from those obtained in other work that OTf or its domains cannot bind to human TfR [19,23]. It was concluded that the mode of binding of OTf and Tf to human TfR are different despite tertiary structural differences fail to reveal any obvious differences between OTf and Tf [19]. In our previous study, we found that reduction with thioredoxin triggered self-cleavage of OTf that made OTf exhibit specific killing of colon and breast cancer cells mediated through induction of apoptosis [24]. In a recent study, we demonstrated that OTf successfully conjugated with hydrophobic antibiotic, and while significantly improve their water solubility it was able to deliver these antibiotics to bacteria intra-cellularly infecting human cells [25]. Although these studies had hypothesized the ability of OTf to be recognized by TfR on human cells, there is no study available regarding the candidacy of OTf as a targeting molecule for anticancer drug delivery. Particularly OTf is abundantly available protein and displays structure feature to accommodate a range of drugs through non-covalent interactions [26] and it is expected to bind TfR on human cell surface. Whether OTf could serve as targeting molecule for anticancer drugs remains to be done, which could be warranted strategy to obtain efficient drug uptake and lesser side effects.

This study was thus aimed to explore the candidacy of OTf as a prospective targeting molecule for anticancer drugs. Antibody to OTf was used to provide evidence that OTf binds TfR on human cancer cells. For this, two anticancer drugs, known to exert unfavorable side effects, were non-covalently conjugated with OTf and the anticancer potencies of the conjugates were investigated.

\section{Materials and Methods}

\section{Materials}

Ovotransferrin, purchased from Inovatech BioProducts Inc (Abbotsford, Canada), was re-crystallized and chromatographically (Sephadex G-50) purified to over 98\%. Antibiotic-antimycotic mixed solution and CF488A-labeled anti-rabbit antibody were from Nacalai Tesque, Inc. (Tokyo, Japan). Paclitaxel and Carboplatin were from Funakoshi(Tokyo, Japan). Rabbit anti-chicken transferrin antibody was from MyBioSource (San Diego, USA). Trypan blue (TB) was from Sigma (St. Louis, MO).

McCoy 5a medium was from ICN (Invitrogen, Japan). CyQuant Direct cell proliferation/toxicity assay kit for animal cells was from Molecular Probes (Invitrogen Japan, Tokyo). Unless otherwise specified, all other reagents were of analytical grade.

\section{Cell lines and cultures}

Human colon carcinoma HCT-116 (ATCC\# CCL-247) cell line was from American Type Culture Collection (Rockville, MD) and human breast cancer MCF-7 (JCRB0134) cell line was from JCRB Cell Bank (Osaka, Japan). HCT-116 cells were maintained in McCoy's 5a media while MCF-7 cells were maintained in E-MEM media with nonessential amino acids and $\mathrm{Na}$-pyruvate. Both media were supplemented with $10 \%$ fetal bovine serum (FBS) and antibiotic-antimycotic solution. Working cultures were maintained at $37^{\circ} \mathrm{C}$ in a humidified incubator with $5 \% \mathrm{CO}_{2}$, and the medium was changed every other day. Cells count and viability were monitored by trypan blue exclusion using TC10" Automated Cell Counter (Bio-Rad).

\section{Preparation of OT $f$-drug conjugates}

Conjugates of OTf with carboplatin (OTf-cbp) or paclitaxel (OTfPTX) were prepared as previously described [25]. Briefly, freshly prepared drug stock solution in 50\% ethanol was added to OTf solution to achieve 3, 7, 15-fold molar excess of drug over OTf in distilled water at $\mathrm{pH} 9.0$. After stirring for $24 \mathrm{~h}$ at $29^{\circ} \mathrm{C}$, the mixture was lyophilized. The conjugates were referred to as OTf-drug3, OTf-drug7 and OTfdrug 15 whereas numbers indicate the mole ratio of the respective drug over OTf. Control (OTf) was treated similarly except without drug.

\section{Binding of drugs to OTf}

Intrinsic protein fluorescence was measured in a $0.5-\mathrm{cm}$ square cuvette thermostated at $25^{\circ} \mathrm{C}$ using a JASCO FP-6600 fluorescence spectrophotometer (JASCO Corp., Tokyo). The excitation wavelength of $285 \mathrm{~nm}$ (5-nm bandwidth) was chosen and the tryptophan fluorescence 
emission spectra were recorded at $300-400 \mathrm{~nm}$ in solutions containing OTf derivatives (at a OTf-based concentration of $0.1 \mathrm{mg} / \mathrm{ml}$ ), or free drugs (at concentration equivalent to their contents in the respective conjugate) in $25 \mathrm{mM} \mathrm{Na}$-phosphate buffer (pH 7.4). The results are representative of two independent experiments performed in duplicate

\section{Transferrin receptor binding}

To confirm the ability of OTf to bind transferrin receptor (TfR) on human carcinoma cells, antibody against OTf were employed. Briefly, HCT- 116 cells were seeded at $5 \times 10^{5}$ cells/well in 8-well chamber slides (SPL, Life Science) and incubated in McCoy's 5a containing $10 \% \mathrm{v} / \mathrm{v}$ FBS for $24 \mathrm{~h}$ at $37{ }^{\circ} \mathrm{C}$ under $5 \% \mathrm{CO}_{2}$ air. At $80 \%$ confluency, cells were washed three times with PBS and fixed with $2 \%$ paraformaldehyde for $10 \mathrm{~min}$. After washing with PBS buffer, cells were treated with OTf or OTf-cbp conjugate in PBS buffer (at $50 \mu \mathrm{g} / \mathrm{ml}$ protein-based concentration). After $1 \mathrm{~h}$, cells were washed three times then wells were treated with blocking agent (Blocking-One, Nacalai tesque, Japan) for $10 \mathrm{~min}$. Then cells were incubated with anti-OTf antibody $\left(1^{\text {st }} \mathrm{IgG}\right)$ in PBS containing $1 \% \mathrm{FBS}$ for $60 \mathrm{~min}$ at $37^{\circ} \mathrm{C}$. As a negative control, a well of OTf-treated cells was incubated with PBS lacking antibody $\left(\Delta 1^{\text {st }}\right.$ $\mathrm{IgG})$. Wells were washed three times with PBS (1\% FBS) and incubated with Alexa Fluor (CF488A)-labeled secondary antibody for $60 \mathrm{~min}$ at $37^{\circ} \mathrm{C}$. Cells were washed three times with PBS and observed with Keyence BZ-9000 fluorescence microscope (Eurotek Inc., USA), under prolong-gold-antifade reagent.

\section{Cell proliferation assay}

CyQuant direct cell proliferation assay was used to assess cell proliferation and cytotoxicity. The assay is based on a cell-permeant DNA-binding dye in combination with a background suppression reagent that blocks staining of dead cells and cells with compromised cell membranes, causing only staining of healthy cells. Therefore, the assay measures proliferation as well as cytotoxicity. Briefly, cells were seeded in 96-well black fluorescence plates, at a density of 5000 cells/ well in duplicates. After $24 \mathrm{~h}$, wells were treated with the respective conjugate at concentration of $50 \mu \mathrm{g} / \mathrm{mL}$ protein-based $(0.64 \mu \mathrm{M}$ $\mathrm{OTf} / \mathrm{L}$ ) in PBS. Mock cells (Control) were treated with PBS alone. After $48 \mathrm{~h}$ of treatment at $37^{\circ} \mathrm{C}$, the media was replaced with fresh media and an equal volume of CyQuant detection reagent (staining dyes and background suppressor) was added. After $60 \mathrm{~min}$ at $37^{\circ} \mathrm{C}$, the fluorescence (RFU) was bottom read at excitation and emission of 480 $\mathrm{nm}$ and $535 \mathrm{~nm}$, respectively, with Infinite M200 FA (Tecan, Japan) plate reader. After subtraction of controls and blank values, RFU readouts were used to calculate the proliferation index as follows:

Proliferation index $=$ RFU of treated cells $x$ (1/RFU of mock cells).

Cell viability was also monitored by trypan blue exclusion of the treated cells using TC10"m Automated Cell Counter (Bio-Rad).

\section{Cytotoxicity assay}

Following incubation for $48 \mathrm{~h}$ of the active conjugates or their derivatives, cytotoxicity of HCT-116 cells was assessed using acridine orange (AO)-propidium iodide (PI) staining and cells were observed via fluorescence microscopy under $20 \times$ magnification with Keyence BZ-9000 fluorescence microscope. Viable cells stain green by AO and dead cells stain red by PI while apoptotic cells denoted by crescentshaped or asymmetrically-localised red nuclei.

\section{Molecular docking simulation of OTf-drug conjugates}

The structure of OTf was generated by the UCSF Chimera (University of California) from PDB files of chicken ovotransferrin (1aiv). Docking analysis was performed by SwissDock ligand-protein dock server (http://www.swissdock.ch/docking) with entries of carboplatin (ZINC404340) or paclitaxel (ZINC96006020).

\section{Results}

\section{Interaction of drugs with OTf}

To delineate the interaction of the drugs with OTf, tryptophan (Trp) residues were utilized as distinct reporters. Trp fluorescence has been a useful tool to monitor conformational changes in proteins and ligand-protein interactions [27]. When buried in a hydrophobic environment, Trp exhibits increase in maximum fluorescence intensity $\left(\mathrm{FI}{ }_{\max }\right)$ and shifts to a shorter (blue shift) maximal wavelength $\left(\lambda_{\max }\right)$. And intensity quenching and red shift is observed when Trp is exposed to the surface. Figure 1 shows the Trp fluorescence emission spectra of OTf and when conjugated with different molar ratios $(3,7$ and 15 moles over OTf) of drugs. The spectrum of control OTf exhibits a peak with $\lambda_{\max }$ at $336 \mathrm{~nm}$ and a steep wavelength tail typical of partially buried Trp within apolar environment. Regardless of the type of drug, conjugation of drugs caused decrease in $\mathrm{FI}_{\text {max }}$ (intensity quenching) of OTf with an increase in the molar ratio of the drug in the conjugate. The spectrum of OTf-cbp (Figure 1A) and OTf-PTX (Figure 1B) conjugates showed blue shift $\left(\lambda_{\text {max }}\right.$ at $\left.334 \mathrm{~nm}\right)$ in the spectrum with an increase in the molar ratio of the drug in the conjugates, indicating the shield (buried) of Trp residues. The blue shift of the OTf-cbp and OTfPTX spectrum accompanied with quenching of fluorescence intensity relative to the control OTf spectra indicate association between OTf and the drug whereas the side chains of Trp residues (fluorophore) seems to be interacting with a quencher (drug) or being located in a hydrophobic environment within OTf molecule.

\section{Binding of OT $f$ to surface receptors on colon cancer cells}

The binding of OTf to the surface receptors of HCT-116 cells was assessed by microscopic detection using anti-OTf antibody and antiantibody tagged with fluorescent ligand. As shown in Figure 2, OTf bound to HCT-116 cells (Figure 2g) particularly the fluorescence was highly intense at the cell surface (solid arrows) and also appeared in the intracellular milieu (dotted arrows), confirming the ability of OTf
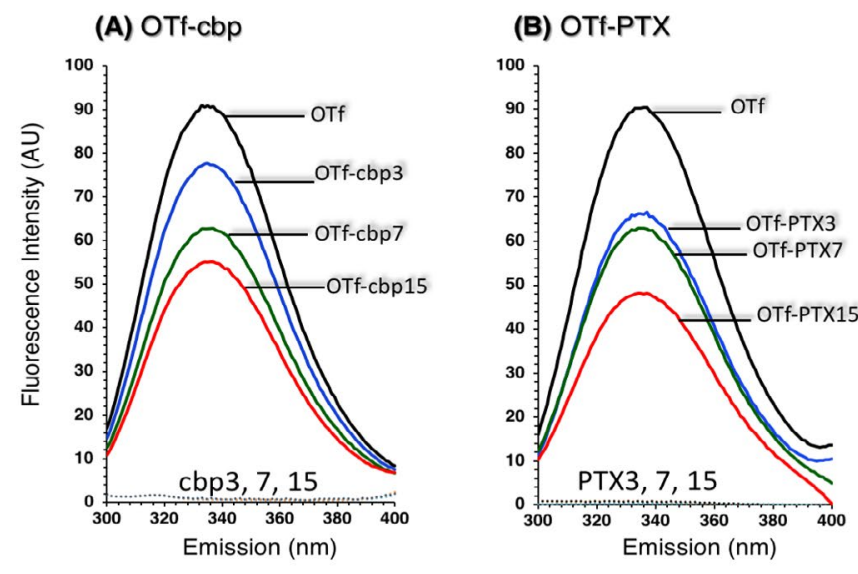

Figure 1. Tryptophan fluorescence emission of OTf conjugated with various mole ratios of cbp (A) or PTX (B) recorded upon excitation at $285 \mathrm{~nm}$. Fluorescence emission was recorded in solutions containing derivatives (at OTf-based concentration of $0.1 \mathrm{mg} / \mathrm{ml}$ ), or drug alone (at concentration equivalent to its content in the respective preparation) in $25 \mathrm{mM}$ Na-phosphate buffer ( $\mathrm{pH}$ 7.4). Numbers (3, 7 and 15) indicate mole ratios of a drug to OTf in the conjugate. OTf, unconjugated OTf. The fluorescence of the drugs has no disturbance due to its negligible emission at the wavelength region of protein (broken arrows)....... 


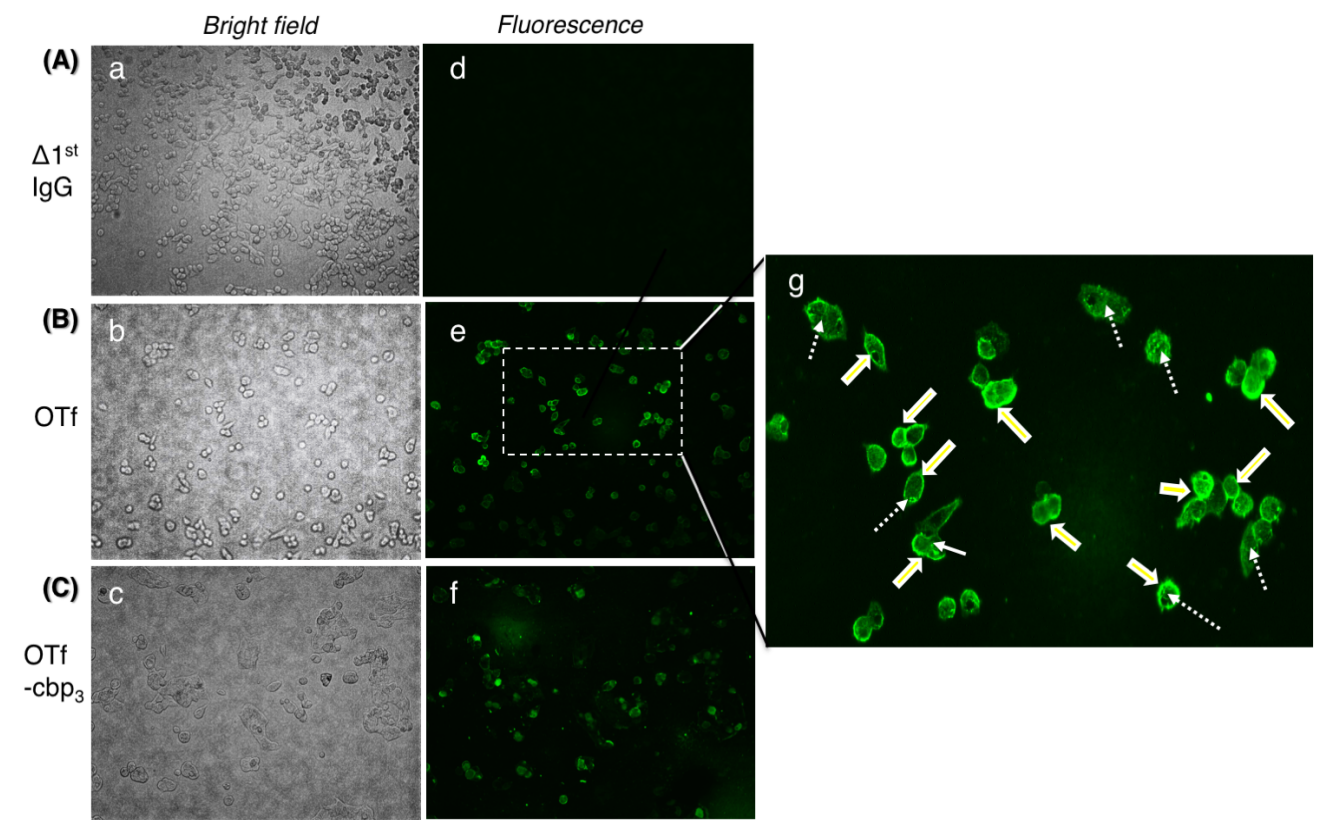

Figure 2. Binding and internalization of OTf or OTf-cbp conjugate into HCT-116 cells. Observation was made under phase contrast (left panels) and fluorescence microscope (right panels) Cell treated without $1^{\text {st }}$ IgG antibody was used as control for non-specific IgG interaction (A). The cells were incubated with OTf (B) or OTf-cbp3 conjugate (C) then after wash, OTf was detected by $1^{\text {st }} \mathrm{IgG}$ anti-OTf antibody flowed by Alexa Fluor 488-labeled $2^{\text {nd }}$ antibody. (g) Fluorescent cells in (e) were magnified to enable visualization of the enhanced fluorescence at the cell membrane. Note OTf bind the surface of the cells (bold arrows) and also located into cells through endocytosis.

to bind TfR and its internalization with TfR complex. The greatly high fluorescence intensity at the surface of HCT-116 cells (Figure $2 \mathrm{~g}$, solid arrows) agree with the observation that the level of TfR expression on cancer cells is several folds higher than on normal cells [28]. Interestingly, conjugation of anticancer drug such as carboplatin (OTf-cbp3) did not affect the binding of OTf to TfR (Figure 2f). The lack of fluorescence signal on cells treated with OTf without anti-OTf antibody (Figure $2 \mathrm{~d}, \Delta 1^{\mathrm{st}} \mathrm{IgG}$ ) indicates the reliable specificity of the assay. The results suggest that the TfR can be targeted by conjugation of anticancer drugs to OTf that is recognized by TfR on cancer cells.

\section{Anti-proliferative activity of the conjugates}

The anti-proliferative activities of OTf-drug conjugates were tested against human colon carcinoma cells, HCT-116 (Figure 3 ) and human breast carcinoma cells, MCF-7 (Figure 4). The activity was expressed as proliferation index of OTf-drug conjugates as well as OTf and drug at concentration equivalent to their doses in the conjugates. In Figure 3, control OTf showed weak anti-proliferative activity against HCT116 , whereas it reduced proliferation to $87 \%$ relative to mock treated cells (Figure 3, OTf). The free cbp drug cbp-3 and cbp-7 showed weak anti-proliferative activities but cbp-15 exhibited strong activity (Figure $3 \mathrm{~A}, \mathrm{cbp}$ ). The OTf-cbp conjugates were remarkably anti-proliferative whereas the low drug loaded conjugate (oc-3) completely ceased proliferation (Figure 3A). The OTf-cbp7 (oc-7) conjugate exhibited anti-proliferative activity similar to the free cbp15 (cbp-15), indicating that conjugation with OTf could cause two-fold decrease in the drug dose. The free PTX drug showed remarkable anti-proliferative activities against HCT-116 while the OTf-PTX conjugates showed higher potency (Figure 3B). The low loaded conjugate (op3) was much effective (Figure 3B).

In order to discern whether the anti-cancer activities of OTf-drug conjugates are specific to colon cancer or can be effective to other cancer cells, anti-proliferative activity was investigated against human breast carcinoma cells, MCF-7 cells (Figure 4). As shown in Figure 4A, the OTf-cbp conjugate with the lowest drug load (oc3) exhibited stronger activity than the conjugates with higher drug load (oc7 and oc15) or their free derivatives, cbp or OTf. Similarly, the OTf-PTX conjugates with low drug load (op3 and op7) exhibited stronger activities than the conjugate with higher drug load (op15) or their free derivatives, PTX or OTf (Figure 4B). The results suggest that the OTf-drug conjugates induce inhibition of cells growth of HCT-116 and MCF-7 and it seems that the low drug loading of OTf in the conjugate ( 3 moles drug/OTf mole) is the most effective against both cancer cells but the effect is more pronounced against HCT-116 cells.

\section{Cytotoxicity of the conjugates}

Carboplatin (cbp) is a platinum-based agent that has the ability to interact with purine bases in the DNA strand, thereby inhibiting replication and transcription, and finally leading to apoptosis [29]. Paclitaxel (PTX) on the other hand arrests cell growth in mitosis through interference of microtubule polymerization [30]. Numerous studies have demonstrated that the actions of cbp and PTX are blocking of cells growth leading to apoptosis [31,32]. Therefore, we tested whether the facilitated delivery of cbp and PTX by OTf could induce apoptosis of HCT-116 cancer cells. The mode of cell death was evaluated by acridine orange $(\mathrm{AO}) /$ propidium iodide $(\mathrm{PI})$ double staining upon treatment with the most active conjugates, OTf-cbp3 (Figure 5) and OTf-PTX3 (Figure 6), compared to their derivatives (free drugs or OTf alone). As shown in the fluorescence microscopy images, bright green round nuclei by $\mathrm{AO}$ are considered viable; faint green nuclei are considered metabolically inactive or dying; and bright red nuclei by PI are considered apoptotic, leaky membrane. In the mock treated HCT-116 (no conjugates or derivatives), cells are intact with bright green round nuclei and no PI red signal was observed, indicating good viability (Figure $5 \mathrm{~A}$ ). Following the treatment with OTf alone (Figure 5B) or free cbp (Figure 5C), few apoptotic red signals were observed. Cells treated with OTf-cbp3 conjugate showed significant number of 

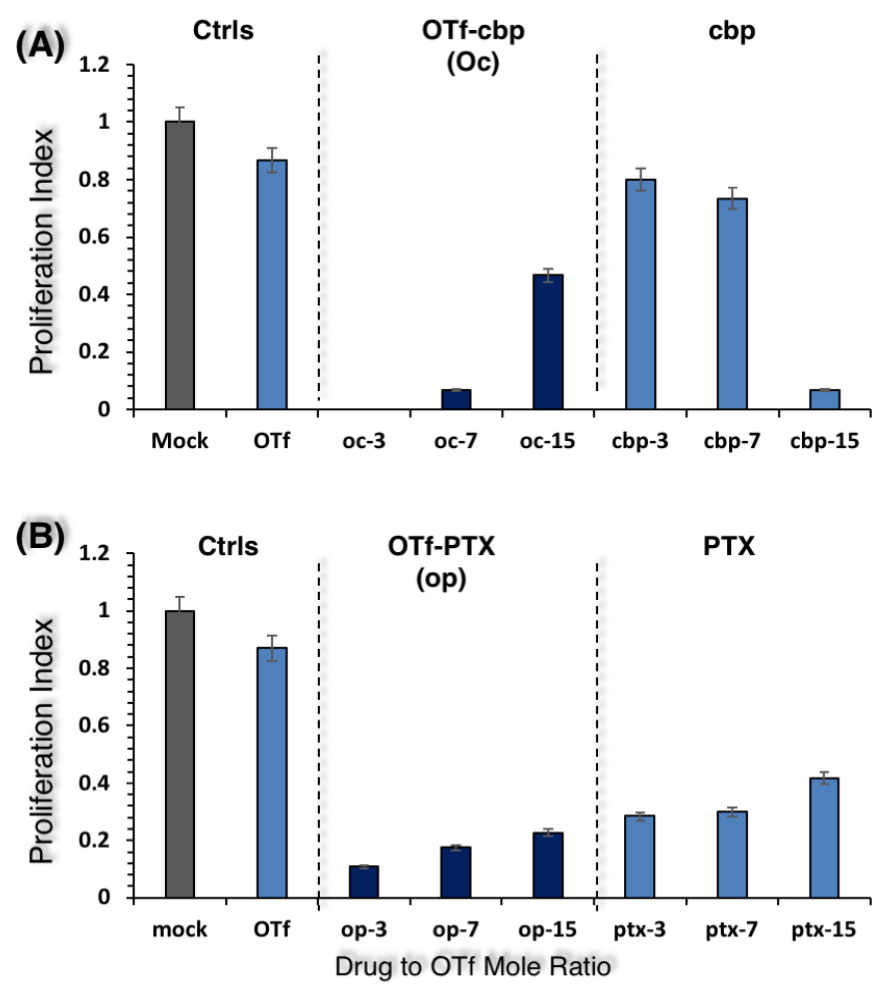

Figure 3. Anti-proliferative activity of OTf-cbp (A) and OTf-PTX (B) conjugates against human colon carcinoma cells (HCT-116). Cells were treated by conjugates or their derivatives free OTf or drug $(50 \mu \mathrm{g} / \mathrm{ml})$ and incubated at $37^{\circ} \mathrm{C}$ for $48 \mathrm{~h}$. The CyQuant direct proliferation assay was performed in a fluoro-microplate by measuring fluorescence at excitation and emission of $480 \mathrm{~nm}$ and $535 \mathrm{~nm}$, respectively. The data is presented as proliferation index calculated as described in Materials and Methods. Values shown represent the mean of two experiments from two parallel wells per sample in each experiment.
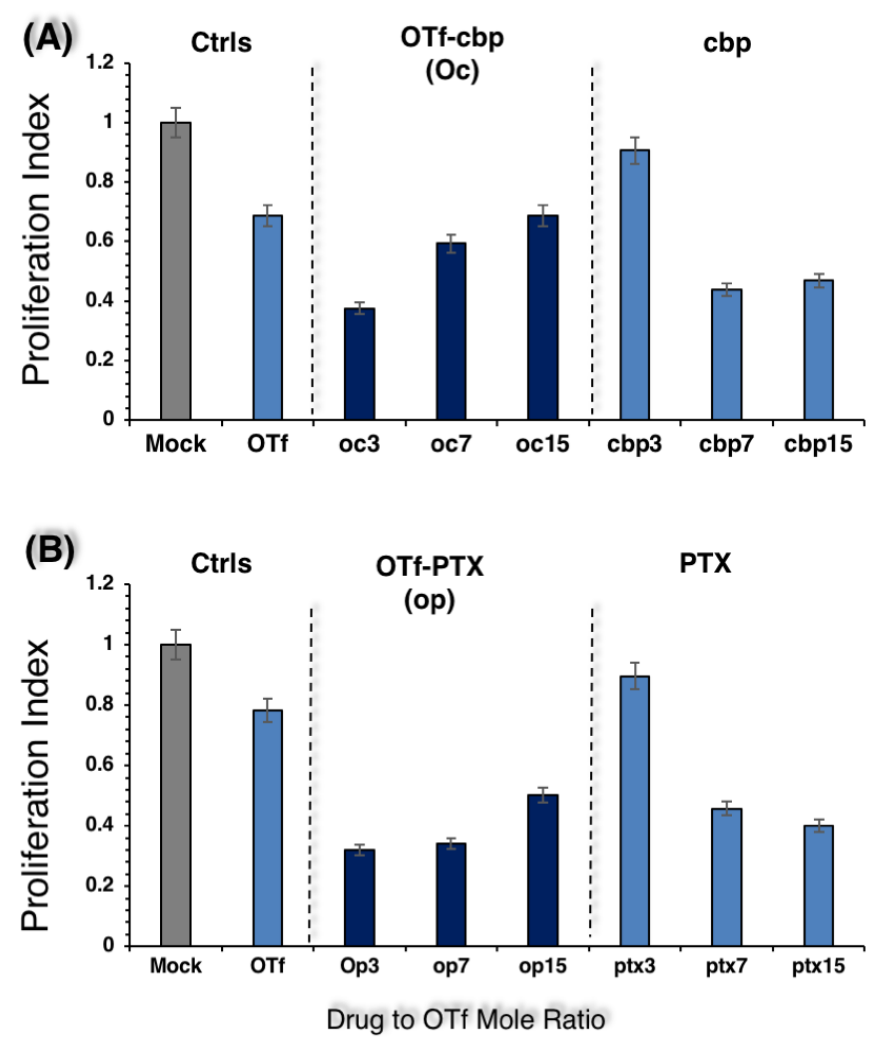

Figure 4. Anti-proliferative activity of OTf-cbp (A) and OTf-PTX (B) conjugates against human breast carcinoma cells (MCF-7). The assay was performed as described under Figure 3 Values shown represent the mean of two experiments from two parallel wells per sample in each experiment. 


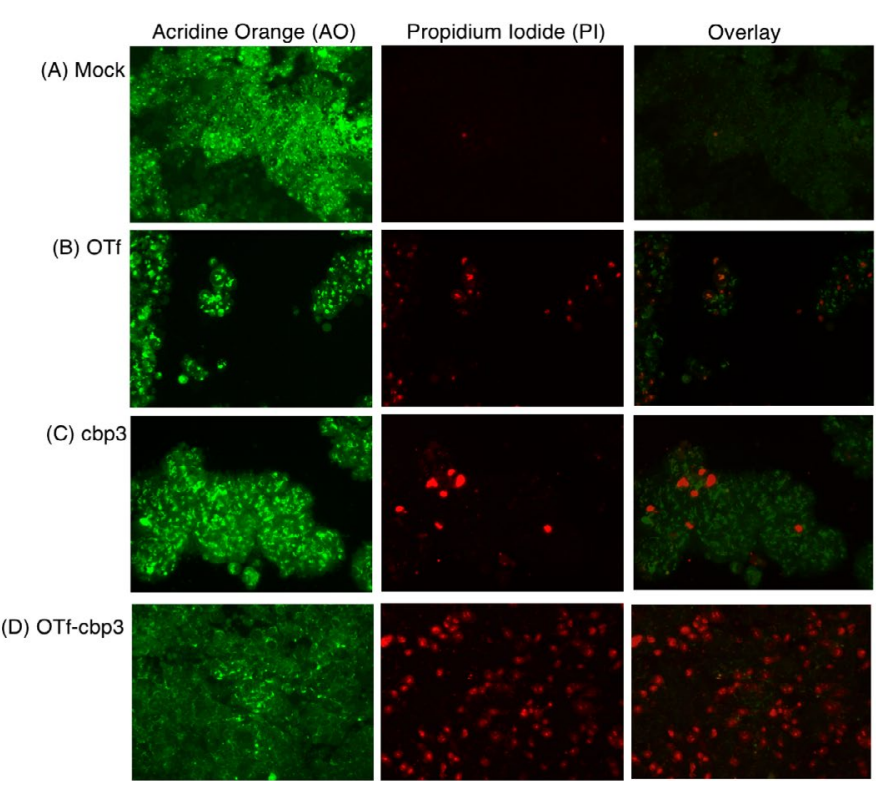

Figure 5. Live and dead HCT-116 cells treated with OTf-cbp3 conjugate or its derivatives detected by acridine orange (AO)/propidium iodide (PI) staining. Mock cells were treated with PBS (A), OTf (B), cbp (C) or OTf-cbp3 (D) for 48h and cytotoxicity observed via fluorescence microscope. Viable cells stain green by AO. Dead or apoptotic cells are stained red by PI, exhibiting asymmetrically localized nuclei.

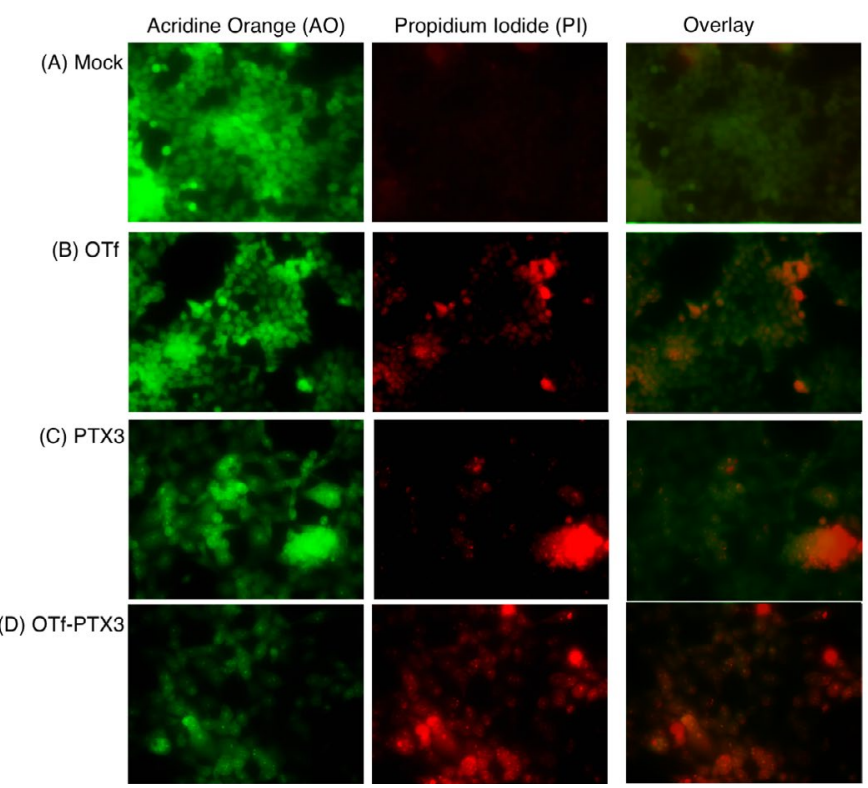

Figure 6. Live and dead HCT-116 cells treated with OTf-PTX3 conjugate or its derivatives detected by acridine orange $(\mathrm{AO})$ /propidium iodide (PI) staining. The assay was performed as described under Figure 5.

fragmented red nuclei with faint green nuclei were observed, indicating apoptosis mediated cytotoxicity (Figure 5D). It can be inferred that OTf-cbp3 conjugate at concentration of $0.64 \mu \mathrm{M}$ OTf-based (loaded with $1.92 \mu \mathrm{M} \mathrm{cbp}$ ) induced apoptosis and subsequent death of HCT116 cells following $48 \mathrm{~h}$ incubation.

A similar trend was observed when the cytotoxicity of OTf-PTX3 conjugate was evaluated by using AO-PI double staining (Figure 6). Treatment of HCT-116 cells with OTf-PTX3 conjugate revealed high proportion of apoptotic cells with red condensed nuclei (Figure 6D). OTf alone (Figure 6B) or free PTX (Figure 6C) treatment produced fewer proportion of apoptotic cells than their OTf-PTX3 conjugate. AO staining of mock- or OTf-treated cells revealed green nuclei without condensation (Figure 6A and 6B). But free PTX3 and OTf-PTX3 treated cells showed clear condensation of bright green nuclei, whereas condensation in the OTf-PTX3 treated cells (Figure 6D) was more pronounced than the free PTX3 (Figure 6C). The results demonstrate that the targeted delivery of cbp and PTX by OTf to colorectal cancer cells, HCT-116, not only enhanced their abilities to inhibit cell proliferation but also facilitated the drugs to trigger apoptotic process.

\section{Discussion}

Synthetic drugs technology has provided new avenues in chemotherapy and become a vital part of advances in curing cancers. Carboplatin and paclitaxel have potential in the treatment of cancers, as they have different intracellular targets. Carboplatin is intercalating agent that interferes with DNA replication, while paclitaxel targets microtubules growth. Despite the major advantages of the development of anticancer synthetic drugs, there is drawback in their biopharmaceutical properties. Paclitaxel (PTX), for example, binds to the $\beta$-tubulin disrupt the dynamics of microtubules which arrests the cells growth and triggers apoptosis in cancer cells [33-35]. However, the chemical structure of PTX results in extremely low water solubility. On the other hand, carboplatin (cbp), a platinum-based drug, is widely used in cancer therapy acting by crosslinking DNA, but its clinical success is limited due to severe side effect as it form complexes with biologically active ligands of immune cells [36].

In this study the efficiency of OTf to serve as a drug carrier to facilitate the delivery of a water-insoluble (PTX) and a platinum-based (cbp) anticancer drugs into cancer cells is explored. Conjugation of the three drugs induced quenching of the tryptophan (Trp) emission, indicating change of tryptophan micro-environment, likely due to interaction with the drugs (Figure 1). The decrease in Trp fluorescence intensity $\left(\mathrm{FI}_{\max }\right)$ has been attributed to electron transfer quenching by carbonyl group $[27,37,38]$.

Interestingly, the maximum wavelength $\left(\lambda_{\max }\right)$ in OTf shifted to shorter wavelength, from 336 to $334 \mathrm{~nm}$ (blue shift), upon binding to PTX and cbp (Figure 2), but binding to PTX caused substantial decrease of $\mathrm{FI}_{\max }$, indicating that the two conformational states of OTf are different. It seems that the two drugs interact by different modes and variable sites within OTf molecule.

The molecule of OTf has two principal domains, N-lobe and C-lobe [39]. As shown in Supplementary information (Figure S1), molecular docking was used to gain insight in the binding of the drugs on OTf molecule. The C-lobe exhibited less binding sites for all drugs used compared to the N-lobe that had many binding sites. Particularly, the binding sites of cbp were mostly within the N-lobe, while the binding sites for PTX were dispersed within the N-lobe and some sites were in the inter-lobes cleft. It was noted that the surface exposed region of $\mathrm{N} 2, \mathrm{C} 1$ and C2 do not have sites for binding of any of the two drugs (Figure S1). Since it has been reported that $\mathrm{N} 2$ and $\mathrm{C} 1$ subdomains are required for binding of OTf to TfR [23], these results offer molecular explanation for the stronger anti-cancer activities of OTf-cbp and OTfPTX than their free drugs (Figure 3 and Figure 4).

We have shown that the conjugates of the two different anticancer drugs with OTf exerted strong anti-proliferative activities against two cancer cell lines, whereas the activities were more pronounced with low drug load to OTf (Figure 3 and Figure 4). Notably, growth inhibition of HCT-116 and MCF-7 cells by OTf-cbp3 was observed at concentration 
as low as $50 \mu \mathrm{g} / \mathrm{ml}$ (OTfbased), while the cells were rarely sensitive to the same concentrations of free cbp (Figure 5 and Figure 6). Interestingly, the conjugates OTf-cbp3 and OTf-PTX3 potently caused much death, PI positive, of human colorectal cancer cell line (HCT-116), while the cells was poorly sensitive to the free OTf or drugs, when test at the same concentration as in the conjugates (Figure 5 and Figure 6). Particularly, OTf-cbp3 was the most effective in killing HCT-116 cells (Figure 5). Taking together, targeting of cbp and PTX by OTf caused cytotoxic effects and induced apoptosis in colon cancer cells more efficiently than the free drugs.

\section{Conclusion}

In conclusion, although the TfR has been explored as a targeting molecule for the treatment of cancers, utilization of an abundant protein from egg albumen (OTf $)$ as targeting molecule could renew interest in OTf-based drug targeting strategy for the treatment of cancer. In our recent work, OTf-based antibiotics targeting strategy was demonstrated effective in the alleviation of intracellular bacterial infections. The present study demonstrates a new approach through TfR-mediated endocytosis with higher efficacy and minimal toxicity to the goal of intervening with the progress of cancers. The OTf-based drug targeting strategy may provide an effective strategy for both basic research and clinical practice with potential to alleviate insolubility problem of many hydrophobic anticancer drugs and reduce side effect toxicity by decreasing the dose of drug taken. Further in vivo studies to analyze the potential use of this approach as an anticancer therapy in the pharmaceutical industries would be highly rewarding.

\section{References}

1. Kratz F, Muller IA, Ryppa C, Warnecke A (2008) Prodrug strategies in anticancer chemotherapy. Chem Med Chem 3: 20-53. [Crossref]

2. Silvia A, Franco D, Barbara S, Luigi C (2011) Anticancer Prodrugs: An Overview of Major Strategies and Recent Developments. Curr Top Med Chem 11: 2346-2381. [Crossref]

3. Farooq MU, Novosad V, Rozhkova EA, Wali H, Ali A, et al. (2018) Gold Nanoparticlesenabled Efficient Dual Delivery of Anticancer Therapeutics to HeLa Cells. Sci Rep 8: 2907. [Crossref]

4. Palanikumar L, Al-Hosani S, Kalmouni M, Nguyen VP, Ali L, et al. (2020) pHresponsive high stability polymeric nanoparticles for targeted delivery of anticancer therapeutics. Commun Biol 3: 95. [Crossref]

5. Wiradharma N, Zhang Y, Venkataraman S, Hedrick JL, Yang YY (2009) Selfassembled polymer nanostructures for delivery of anticancer therapeutics. Nano Today 4: 302-317. [Crossref]

6. Chen J, Almo SC, Wu Y (2017) General principles of binding between cell surface receptors and multi-specific ligands: A computational study. PLoS Comput Biol 13: e1005805. [Crossref]

7. Janssen S, Depoortere I (2013) Nutrient sensing in the gut: new roads to therapeutics? Trends Endrocrinol Metab 24: 92-100. [Crossref]

8. Cao Y, Koh X, Dong L, Du X, Wu A, et al. (2011) Rapid Estimation of Binding Activity of Influenza Virus Hemagglutinin to Human and Avian Receptors. PLoS One 6: e18664. [Crossref]

9. Le Poul E, Loison C, Struyf S, Springael JY, Lannoy V, et al. (2003) Functional characterization of human receptors for short chain fatty acids and their role in polymorphonuclear cell activation. J Biol Chem 278: 25481-25489. [Crossref]

10. Tang Y, Chen Y, Jiang H, Robbins GT, Nie D (2011) G-protein-coupled receptor for short-chain fatty acids suppresses colon cancer. Int J Cancer 128: 847-856. [Crossref]

11. Shen Y, Li X, Dong D, Zhang B, Xue Y, et al. (2018) Transferrin receptor 1 in cancer: a new sight for cancer therapy. Am J Cancer Res 8: 916-931. [Crossref]

12. Daniels TR, Bernabeu E, Rodríguez JA, Patel S, Kozman M, et al. (2012) The transferrin receptor and the targeted delivery of therapeutic agents against cancer. Biochim Biophys Acta 1820: 291-317. [Crossref]
13. Kelter G, Steinbach D, Konkimalla VB, Tahara T, Taketani S, et al. (2007) Role of Transferrin Receptor and the ABC Transporters ABCB6 and ABCB7 for Resistance and Differentiation of Tumor Cells towards Artesunate. PLoS One 2: e798. [Crossref]

14. Gaffney JP, Valentine AM (2012) Beyond bilobal: Transferrin homologs having unusual domain architectures. Biochim Biophys Acta 1820: 212-217. [Crossref]

15. Cimini A, Mei S, Benedetti E, Laurenti G, Koutris I, et al. (2012) Distinct cellular responses induced by saporin and a transferrin-saporin conjugate in two different human glioblastoma cell lines. J Cell Physiol 227: 939-951. [Crossref]

16. Weaver M, Laske DW (2003) Transferrin receptor ligand-targeted toxin conjugate (TfCRM107) for therapy of malignant gliomas. J Neurooncol 65: 3-14. [Crossref]

17. Giannetti AM, Snow PM, Zak O, Bjorkman PJ (2003) Mechanism for multiple ligand recognition by the human transferrin receptor. PLoS Biol 1: E51. [Crossref]

18. Mason AB, Brown SA, Church WR (1990) A highly conserved surface loop in the C-terminal domain of ovotransferrin (residues 570-584) is remote from the receptorbinding site. Biochem J 266:393-398. [Crossref]

19. Wally J, Buchanan SK (2007) A structural comparison of human serum transferrin and human lactoferrin. Biometals 20: 249-262. [Crossref]

20. Łubgan D, Jóźwiak Z, Grabenbauer GG, Distel LVR (2009) Doxorubicin-transferrin conjugate selectively overcomes multidrug resistance in leukaemia cells. Cell Mol Biol Lett 14: 113-127. [Crossref]

21. Wang F, Jiang X, Yang DC, Elliott RL, Head JF (2000) Doxorubicin-gallium-transferrin conjugate overcomes multidrug resistance: Evidence for drug accumulation in the nucleus of drug resistant MCF-7/ADR cells. Anticancer Res 20: 799-808. [Crossref]

22. Rochard E, Legrand D, Mazurier J, Montreuil J, Spik G (1989) The N-terminal domain I of human lactotransferrin binds specifically to phytohemagglutinin-stimulated peripheral blood human lymphocyte receptors. FEBS Lett 255: 201-204. [Crossref]

23. Mason AB, Brown SA, Church WR (1987) Monoclonal antibodies to either domain of ovotransferrin block binding to transferrin receptors on chick reticulocytes. $J$ Biol Chem 262: 9011-9015. [Crossref]

24. Ibrahim HR, Kiyono T (2009) Novel Anticancer Activity of the Autocleaved Ovotransferrin against Human Colon and Breast Cancer Cells. J Agri Food Chem 57: 11383-11390. [Crossref]

25. Ibrahim HR, Tatsumoto S, Ono H, Van Immerseel F, Raspoet R, et al. (2015) A novel antibiotic-delivery system by using ovotransferrin as targeting molecule. Eur J Pharm Sci 66: 59-69. [Crossref]

26. Ibrahim HR (2000) Ovotransferrin: Chemistry and Antimicrobial Function. in Natural Food Antimicrobial Systems. Edited by Naidu AS. FL, CRC Press Inc, 211-226. [Crossref]

27. Yammine A, Gao J, Kwan AH (2019) Tryptophan Fluorescence Quenching Assays for Measuring Protein-ligand Binding Affinities: Principles and a Practical Guide. Bio Protocol 9: e3253. [Crossref]

28. Daniels TR, Delgado T, Rodriguez JA, Helguera G, Penichet ML (2006) The transferrin receptor part I: Biology and targeting with cytotoxic antibodies for the treatment of cancer. Clin Immunol 121: 144-158. [Crossref]

29. Castrellon AB, Pidhorecky I, Valero V, Raez LE (2017) The Role of Carboplatin in the Neoadjuvant Chemotherapy Treatment of Triple Negative Breast Cancer. Oncol Rev 11: 324. [Crossref]

30. Fujie Y, Yamamoto H, Ngan C, Takagi A, Hayashi T, et al. (2005) Oxaliplatin, a Potent Inhibitor of Survivin, Enhances Paclitaxel-induce Apoptosis and Mitotic Catastrophe in Colon Cancer Cells. Jpn J Clin Oncol 35: 453-463. [Crossref]

31. He P, Ge R, Mao W, Chung P, Ahn J, et al. (2018) Oxidative stress induced by carboplatin promotes apoptosis and inhibits migration of $\mathrm{HN}-3$ cells. Oncol Lett 16 : 7131-7138. [Crossref]

32. Pan Z, Avila A, Gollahon L (2014) Paclitaxel induces apoptosis in breast cancer cells through different calcium--regulating mechanisms depending on external calcium conditions. Int J Mol Sci 15: 2672-2694. [Crossref]

33. Marupudi NI, Han JE, Li KW, Renard VM, Tyler BM, et al. (2007) Paclitaxel: a review of adverse toxicities and novel delivery strategies. Expert Opin Drug Saf 6: 609-621. [Crossref]

34. Singh S, Dash AK (2009) Paclitaxel in cancer treatment: perspectives and prospects of its delivery challenges. Crit Rev Ther Drug Carrier Syst 26: 333-372. [Crossref]

35. Wang F, Porter M, Konstantopoulos A, Zhang P, Cui H (2017) Preclinical developmen of drug delivery systems for paclitaxel-based cancer chemotherapy. J Control Release 267: 100-118. [Crossref] 
36. Dilruba S, Kalayda GV (2016) Platinum-based drugs: past, present and future. Cancer Chemother Pharmacol 77: 1103-1124. [Crossref]

37. Adams PD, Chen Y, Ma K, Zagorski MG, Sönnichsen FD, et al. (2002) Intramolecular quenching of tryptophan fluorescence by the peptide bond in cyclic hexapeptides. $J$ Am Chem Soc 124: 9278-9286. [Crossref]
38. Royer CA (2006) Probing Protein Folding and Conformational Transitions with Fluorescence. Chem Rev 106: 1769-1784. [Crossref]

39. Mason AB, Woodworth RC, Oliver RW, Green BN, Lin LN, et al. (1996) Association of the two lobes of ovotransferrin is a prerequisite for receptor recognition. Studies with recombinant ovotransferrins. Biochem J 319: 361-368. [Crossref]

Copyright: $@ 2020$ Ibrahim HR. This is an open-access article distributed under the terms of the Creative Commons Attribution License, which permits unrestricted use, distribution, and reproduction in any medium, provided the original author and source are credited. 